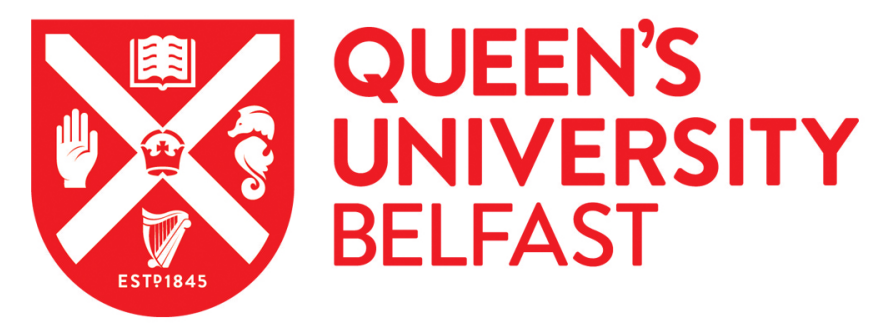

\title{
The inclusion of LGBT+ health issues within undergraduate healthcare education and professional training programmes: A systematic review
}

McCann, E., \& Brown, M. (2018). The inclusion of LGBT+ health issues within undergraduate healthcare education and professional training programmes: A systematic review. Nurse Education Today, 64, 204-214. https://doi.org/10.1016/j.nedt.2018.02.028

Published in:

Nurse Education Today

Document Version:

Peer reviewed version

Queen's University Belfast - Research Portal:

Link to publication record in Queen's University Belfast Research Portal

\section{Publisher rights}

Copyright 2018 Elsevier.

This manuscript is distributed under a Creative Commons Attribution-NonCommercial-NoDerivs License

(https://creativecommons.org/licenses/by-nc-nd/4.0/), which permits distribution and reproduction for non-commercial purposes, provided the author and source are cited.

\section{General rights}

Copyright for the publications made accessible via the Queen's University Belfast Research Portal is retained by the author(s) and / or other copyright owners and it is a condition of accessing these publications that users recognise and abide by the legal requirements associated with these rights.

\section{Take down policy}

The Research Portal is Queen's institutional repository that provides access to Queen's research output. Every effort has been made to ensure that content in the Research Portal does not infringe any person's rights, or applicable UK laws. If you discover content in the Research Portal that you believe breaches copyright or violates any law, please contact openaccess@qub.ac.uk. 
THE INCLUSION OF LGBT+ HEALTH ISSUES WITHIN UNDERGRADUTE HEALTHCARE EDUCATION AND PROFESSIONAL TRAINING PROGRAMMES: A SYSTEMATIC REVIEW

\section{ABSTRACT}

Background: An inclusive health curriculum within undergraduate and continuing professional development programmes (CPD) should include issues related to people whom identify as LGBT+.

Objectives: The aim of this systematic review was to examine the education and training requirements of undergraduate students and health professionals regarding the inclusion of LGBT+ health.

Design: A systematic review of the available published empirical studies.

Data sources: A systematic literature search was undertaken of the following databases: CINAHL, PubMed, PsycINFO, Embase and Sociological Abstracts. All papers reviewed were from the years 2007 to 2017 and written in English.

Review methods: Three research questions informing the literature review were: (i) What are the education and training requirements of undergraduate students and health professionals regarding the health needs of LGBT+ people? (ii) What are the approaches utilized in the education and training of undergraduate students and health professionals regarding the health needs of LGBT+ people? (iii) What are the best practice examples of the education and training of undergraduate students and health professionals? Following the application of definitive criteria, 22 papers were included in the review. Quality appraisal and data extraction was undertaken by two of the authors. Results: The 22 papers were reviewed in detail in the final data analysis and synthesis where four main themes were identified: (1) Cultural competence and inclusivity. (2) Existing knowledge of 
LGBT+ health-related issues. (3) Curriculum developments and outcomes. (4) Evidence of best practice in education delivery.

Conclusion: The review highlights the importance of the inclusion of LGBT+ health-related issues within the health curriculum and continuing professional development programmes and the implications for education and training, clinical practice and research.

\section{Keywords}

LGBT + , health education, health professionals, systematic review, medicine, nursing, allied health 


\section{Introduction}

To be more fully inclusive of the range of sexual and gender identities, including groups such as asexual, intersex, questioning and queer, the contemporary umbrella term LGBT+ is now being more widely adopted (Formby 2017; Fredriksen-Goldsen 2016). This is the term used throughout this paper.

There is a global interest in providing access to adequate healthcare for all (Australian Human Rights Commission 2014; Department of Health 2013; Ontario Human Rights Commission 2014), and to specific groups such as people whom identify as lesbian, gay, bisexual (Institute of Medicine 2011; Royal College of Nursing 2016; Royal College of Nursing 2017; World Health Organization 2013). However, while this is laudable, there remains significant gaps, in for example, the research evidence-base focusing on the distinct needs of people who are transgender and intersex. This is despite the existing concerns around social inclusion, human rights, discrimination and marginalisation (McCann and Brown 2017) and the challenges and negative attitudes faced by LGBT+ people when accessing and using health services (Dearing and Hequembourg 2014; Mayock et al. 2008; Stewart and O'Reilly 2017).

\section{Background}

There is clear evidence of the distinct health needs and service requirements of people whom identify as LGBT+. Physical health needs include sexually transmitted infections (STIs) including Human immuno-deficiency virus (HIV), hepatitis (Cahill and Makadon 2013; The Royal College of General Practitioners (Northern Ireland) 2015). Mental health conditions are also prevalent such as anxiety, depression, self-harm, suicidal ideation, attempted suicide and drug and alcohol use (King et al. 2008; Kuyper \& Fokkema 2011; McCann and Sharek 2016). Furthermore, there are wider psychosocial issues that can have negative consequences for LGBT+ people. Prejudice, discrimination and victimization experiences can have a profound effect upon a person's 
well-being and may result in minority stress (Hendricks \& Testa 2012; Meyer 2015). The minority stress model demonstrates the potential damaging effects of internalized homophobia, biphobia and transphobia. These negative societal reactions to an LGBT+ identity can lead to poor psychosocial outcomes including anxiety, depression, drug use and suicidality (Bariola et al. 2015; Grossman et al. 2011; McCann and Sharek 2016). Also, stigma-related experiences can have a significant impact upon health service access and utilization (Bauer at al. 2009, Grant et al. 2011; McCann and Sharek 2013).

To facilitate an improved healthcare experience, it is necessary to make available a responsive, appropriate and well-resourced health services that is delivered by knowledgeable and skilled health practitioners (Health Service Executive 2009; Institute of Medicine 2011; Transgender Equality Network Ireland 2013). There is an important role for higher education providers and health services to support the development of curricula that can reach all groups, including people who identify as LGBT+ (Lim and Bernstein 2012). Existing studies have looked at developing cultural sensitivity and the enhancement of cultural competence in health training programmes such as psychiatry (Willen, 2013), dentistry (Behar-Hoenstein and Feng 2017), physician assistant training (PA) (Kelly, 2012) and nursing (Sirota 2013). Other studies have investigated heteronormativity in healthcare and education and the potential impact on the student learning experience (Ripley et al. 2012, Singer 2015) and ultimately on the lives of LGBT+ service users (Enson 2015). Significant gaps still exist in the preparation of culturally competent practitioners in both education and health service delivery. Therefore, it is the purpose of this review to examine the education and training requirements of health practitioners, identify good practice examples and to make recommendations for developments in practice, research, education and training. 


\section{Methods}

\subsection{Aim}

The aim of this systematic review was to identify the educational needs of undergraduate students and health professionals and the approaches used in their education and in relation to people who identify as LGBT+. The review questions were:

1. What are the education and training requirements of undergraduate students and health professionals regarding the needs of LGBT+ people?

2. What are the approaches utilized in the education and training of undergraduate students and health professionals regarding the needs of LGBT+ people?

3. What are the best practice examples of the education and training of undergraduate students and health professionals?

\subsection{Design}

The systematic review was guided by recognized methods that supported the development of 'mapping' and narrative integration' of the data (Arskey and O'Malley 2005).

\subsection{Inclusion criteria}

The inclusion criteria were limited to academic journals and peer reviewed empirical studies written in English. Studies were included that focused specifically on the education of undergraduate students and training of health professionals about the needs of LGBT+ people. The education and training approaches utilized and examples of good educational practices were also included.

\subsection{Participants}

The review considered studies that included the views of undergraduate students and healthcare professionals and educators regarding LGBT+-specific issues.

\subsection{Phenomena of interest}

The review examined the experiences of healthcare professionals, undergraduate students and educators regarding the needs of LGBT+ people. 


\subsection{Study types}

The review included peer-reviewed studies that used quantitative, qualitative or mixed methods approaches.

\subsection{Search and selection strategy}

A subject Librarian assisted in devising the literature search strategy. The databases used in the search were CINAHL, MEDLINE, PsycINFO and Sociological Abstracts. The search terms used included gay, lesbian, bisex*, intersex*, transgender*, education, training, curricul*, physician*, doctor*, nurs*, health professional. Boolean operators AND/OR were used. The data were published from August 2007 to August 2017. An example of the search strategy used in one electronic database is shown in Table 1.

***Insert Table 1 here***

The PRISMA method for reporting the results of the searches was used (Moher et al. 2015) (see Figure 1). The searches revealed 943 hits across all the databases. These were screened and irrelevant and duplicates were removed leaving 325 papers that were further screened by title and abstract. A total of 37 full text articles were assessed against the eligibility criteria and a further 16 excluded. The primary reasons for exclusion included: not focusing specifically on education and LGBT+ people; not explicitly addressing LGBT+ issues; were commentary, discussion, opinion and position papers. This left a total of 22 studies that were included for full review and synthesis (see Figure 1).

*** Insert Figure 1 here $* * *$ 


\subsection{Quality assessment}

A quality assessment tool, the Critical Appraisal Skills Programme (CASP) was used as framework to review the papers. (Critical Appraisal Skills Programme, 2013). Relevant questions were applied to the individual studies (Table 2). Each question was scored zero, one or two out of a possible 20 points. A score of zero was given if the paper contained no information, one if there was a moderate amount, and a score of two if the question was fully addressed (Rushbrooke, Murray \& Townsend 2014). A total of 13 studies scored 17 and above (Bidell et al. (2017), Carabez et al. (2015b, Daley \& MacDonnell 2015, Echezona-Johnson 2017, Grosz et al. 2017, Kelley et al. 2008, Lim et al. 2015, Obedin-Maliver et al. 2011, Parameshwaran et al. 2017, Rogers et al. 2013, Strong and Folse 2014, Walsh and Hendrickson 2015, White et al. 2015). A total of 9 studies scored between 14 and 16, indicating gaps and limitations in relation to aims, data collection methods, and ethical concerns (Carabez et al. 2015a, Cheng \& Yang 2015, Corliss et al. 2007, Fredriksen-Goldsen et al. 2011, Gendron et al. 2013, Hardacker et al. 2014, Röndahl 2011, Sequeria et al. 2012, Vance et al. 2017). None of the studies scored less than 14 and all studies were considered suitable for the systematic review as they addressed and met the inclusion criteria.

*** Insert Table 2 here $* * *$

\subsection{Characteristics of the selected studies}

The 22 studies that addressed the aim of the systematic review are contained in Table 3 . Most of the selected studies $(n=18)$ were conducted in the USA. The remaining countries were Canada $(n=1)$, Sweden $(n=1)$, Taiwan $(n=1)$ and UK $(n=1)$. Only two studies had a trans* specific focus. Studies included students, health professionals and faculty members. A significant number 
of studies investigated nursing $(n=8)$ and medical students' $(n=7)$ experiences of LGBT+ issues. One study involved both nursing and medical students. Some of the studies involved interprofessional groups $(n=4)$ and allied health professionals $(n=2)$. Data collection techniques included qualitative methods (interviews, online postings, documentary and observational) $(n=7)$, quantitative methods (surveys and measures) $(n=9)$ and mixed methods (surveys with comments, survey and measures, survey and focus groups $(n=6)$. Participant numbers varied between 9 and 1,231 .

** Insert Table 3 here $* * *$

\subsection{Data extraction and analysis}

The process of data analysis and synthesis involved the extrapolation of themes that addressed the aims of the research. These were coded from the results of the included studies, organised according to concepts and verified and agreed by the research team (Mays et al, 2005).

\section{Findings}

The aim of this systematic review was to consider the literature around the education of undergraduate students and the training of health professionals in relation to people whom identify as LGBT+. Following analysis of the included studies, four main themes emerged from the data: (1) Cultural competence and inclusivity. (2) Existing knowledge of LGBT+ health-related issues. (3) Curriculum developments and outcomes. (4) Evidence of best practice in education delivery and evaluation. Each theme is presented and discussed in turn. 


\subsection{Developing cultural competence and inclusivity}

It has become clear, through this review, that issues exist around the development of cultural competence to enable practitioners to deliver care and supports in culturally responsive, sensitive and inclusive ways (Corlis et al., 2007; Fredriksen-Goldsen et al., 2011; Carabez et al., 2015b; Chen and Yang, 2015; Walsh and Hendrickson, 2015; Echenzona-Johnson, 2017; Parameshwaran et al., 2017). In one UK study involving medical students, where almost $85 \%$ of participants reported a distinct lack of LGBT+ education, nearly half said that they would not routinely ask about sexuality or gender identity needs when assessing patients. Students admitted feeling a lack of confidence and poorly prepared regarding LGBT+-specific health care terminology and this may lead to miscommunication and potential shortcomings in the provision of adequate health and social care (Parameshwaran et al., 2017). Some education programmes, identified in this review, had attempted to embed suitable LGBT+ content into their curricula, however with varying levels of success. Identified barriers included student and staff negative attitudes including preconceptions and biases about LGBT+ people (Fredriksen-Goldsen et al., 2011;) stereotypical beliefs (Carabez et al., 2015b) gendered values (Chen and Yang, 2015) and an acceptance of the prevailing heteronormative practices and policies (Daley and MacDonnell, 2015). Some commentators have argued that nursing and allied health practices and procedures remain predominately 'heterosexist' (Röndahl, 2011; Carabez et al., 2015b). Ways in which health practitioners may be helped and supported in their work among LGBT+ populations is through the provision of adequate education and training initiatives. Nurses and others need to be able to explore their own attitudes, beliefs and preconceptions; explore LGBT+ specific physical and psychosocial needs and develop the confidence and skills to respond competently and confidently with the necessary supports and requirements of LGBT+ people, their friends and families 
(Carabez et al., 2015b; Walsh and Hendrickson, 2015; Echezona-Johnson, 2017). Furthermore, a robust LGBT+ curriculum within undergraduate health programmes would have widespread appeal by offering a specific focus on interpersonal and communication skills, health knowledge and appropriate terminology, and cultural competency; essential components in student and practitioner professional development (Obedin-Maliverat al., 2011; Sequeria et al., 2012; Lim et al., 2015). The most effective way to promote equitable access to services for all is to provide education and training for both undergraduate students and healthcare practitioners that equips them with competent knowledge and skills for the delivery of affirming, respectful and socially inclusive care (Lim et al., 2015; Parameshwaran et al., 2017).

\subsection{Existing knowledge of LGBTQ health related issues}

A recurring theme across a number of studies related to the limited, variable and often patchy inclusion of LGBT+ health within the undergraduate curriculum for student doctors, nurses and other health professionals. Therefore, there is a need to develop the knowledge, skills and understanding of undergraduate students undertaking preparation as healthcare professionals and continuing professional development for existing professionals of the specific health needs and concerns of LGBT+ people (Corliss et al., 2007; Kelley et al, 2008; Obedin-Maliver et al., 2011; Gendron et al, 2013; Hardacker et al., 2014; Carabez et al., 2015a; Dale \& MacDonnell 2015; Lim et al., 2015; Strong and Folse 2014; Vance et al., 2017; Bidell et al., 2017; Echezona-Johnson 2017; Grosz et al, 2017).

Central to addressing the health needs and concerns of LGBT+ people is the need to proactively integrate the subject area within the undergraduate health curriculum for all students (Kelley et al., 2008; Strong and Folse 2014; Grosz et al., 2017). From an undergraduate and 
Continuing Professional Development (CPD) perspective, undertaking pre-baseline assessments of the knowledge, attitudes, values, confidence and perceived capabilities and learning needs is an important starting point when integrating LGBT+ issues and concerns within the health education curriculum (Carabez et al., 2015a; Bidell et al., 2017). A range of approaches to teaching and learning have been advocated to support the delivery of LGBT+ health issues within the curriculum. They include the need to develop new LGBT+-sensitive education materials, multilingual learning resources and the use of e-learning technologies and Problem-Based Learning (PBL) to increase and widen access and participation (Röndahl 2011; Genderon et al., 2013; Hardacker et al., 2014; Vance et al., 2017). Clinical skills simulation can be used to enable undergraduate students to challenge negative and stereotyping beliefs regarding LGBT+ people and build and develop confidence and skills (Röndahl 2011). Clinical attachments and practice assessments offer the opportunity for undergraduates to develop skills in sexual history taking, formulating interventions, increasing self-awareness of inclusive practices and developing cultural competence and LGBT+ sensitive care and support skills (Kelley et al., 2008; Strong and Folse 2015; White et al., 2015).

Continuing Professional Development (CPD) for health professionals is also an area that requires attention and development to ensure that they have the knowledge and skills necessary to address issues related to personal attitudes and values, discrimination, prejudice, stigma and oppression that enables the delivery of culturally competent health care to LGBT+ people now and in the future (Carabez et al., 2015a; Daley \& MacDonnell 2015; Bidell et al., 2017). Evidence further highlights that many health professionals have limited previous education and practice development regarding LGBT+ health issues and concerns beyond the care and support of patients with HIV and AIDS (Corliss et al., 2007). Several approaches to the delivery of LGBT+ 
professional development opportunities have been suggested. They include, developing new LGBTQ education tools and resources, the use of workshops and train-the-trainer programmes and education available in multi-lingual formats and flexible on-line learning materials to enable wider access (Corliss et al., 2007; Fredriksen-Goldsen et al., 2011; Hardacker et al., 2014; Daley \& MacDonnell 2015; White et al., 2015).

Prior to the delivery of both undergraduate and CPD education is the need to undertake pre-assessments of undergraduate students and health practitioners of their preparedness, attitudes, values, experiences and knowledge of LGBT+ psychosocial health needs and concerns (Bidell et al., 2017). The use of self-assessments prior to delivery of the education can also act to raise and increase student self-awareness by facilitating individual reflection and of the impact of learning about LGBT+ health and enable the identification of future learning needs and areas requiring further development (Carabez et al., 2015a; Bidell et al., 2017). Post curriculum delivery evaluation is also necessary at different time points to evaluate the effectiveness and impact of the education to identify changes in knowledge, skills, attitudes, confidence and competence to meet the needs of LGBT+ people (Carabez et al., 2105a). The use of formative and summative assessments to identify learning and development of knowledge, skills, confident and competence regarding LGBT+ health is also required as an integral part of curriculum delivery.

\subsection{Curriculum evaluation and research}

A recurring theme emerging from this review is the need for formal evaluation and research of the integration of LGBT+ needs within the health curriculum (Corliss et al., 2007; Kelley et al., 2008; Gendron et al., 2013; Rogers et al., 2013; Carabez et al., 2015a; Daley \& MacDonald 2015; White et al., 2015; Biddell et al., 2017; Echezona-Johnson 2017; Grosz et al., 2017). Undertaking initial base-line evaluations of the existing knowledge, experiences, skills, values attitudes and 
understanding of the health and wider care and support needs of LGBT+ people is an area that needs to be incorporated into the curriculum at the outset (Carabez et al., 2015a; Bidell et al., 2017). There is an absence of post-curriculum evaluations that formally reviews and identifies the impact and outcomes that have been achieved through the inclusion and delivery of LGBT+ health; this is an area that needs to be incorporated and reviewed against the program learning aims and outcomes (Gendron et al., 2013; Daley \& MacDonald 2015; White et al., 2015; Echezona-Johnson et al., 2017). Formative and summative assessments and examinations also offer an opportunity to review learning and the understanding of students following the integration of LGBT+ health needs within courses (Carabez et al., 2015a).

As LGBT+ health is more widely integrated within the curriculum of undergraduate student and within CPD programmes for health practitioners, there is a need to undertake longitudinal studies that identifies the impact on practice. Longitudinal studies and long-term curriculum evaluations should aim to identify changes and development of positive attitudes and values towards LGBT+ people and in knowledge of their specific health and support needs that goes beyond the 'traditional' sexual health issues, such as HIV and AIDS (Gendron et al., 2013; Daley \& MacDonald 2015). Longitudinal studies also offer the opportunity for national and international collaborations that follow-up undergraduate students as they move forward into their professional careers to identify sustained changes in attitudes, values and knowledge and skills acquisition (Kelley et al., 2008; Gendron et al., 2013; Rogers et al., 2013; Grosz et al., 2017). Longitudinal studies including the views and experiences of LGBT+ people of health professionals and their healthcare experiences also need to be undertaken (Corliss et al., 2007; FrediksenGoldsen et al., 2011). 


\subsection{Evidence of best practice in education delivery}

The review has revealed important shortcomings in adequately addressing LGBT+ concerns within both current undergraduate health education and continuing professional development training programmes. However, useful information has emerged from the existing research that may inform future curricular developments. Several studies highlighted specific approaches and strategies to enhance and support student learning experiences in relation to knowledge, attitudes and the development of cultural competence in caring for LGBT+ people (Bidell et al. 2017; Vance et al. 2017; Carabez et al. 2015a; Gendron et al. 2013; Sequeria et al 2012). A range of methods were used including presentations, scripted interview sessions, groupwork and e-learning technologies (Vance et al. 2017). To highlight particular psychosocial issues faced by older LGBT+ people such as invisibility, social isolation and discrimination, the use of training panels was evaluated among inter-professional health practitioners $(\mathrm{n}=605)$. A significant proportion of participants (94\%) found the training beneficial to their own practice such as increasing knowledge, facilitating self-reflection and promoting a deeper understanding and acceptance of pertinent issues faced by people who identify as LGBT (Rogers et al. 2013). Another positive example of innovative approaches to teaching and learning was a student-led session by medical students delivered to first-year student colleagues. It consisted of a presentation, a patient panel and a group discussion. Participants particularly valued the patient panel and rated their experience highly in terms of preparedness, comfort and confidence (Grotz et al. 2017). Experiential exercises using interview scenarios have been utilized to develop cultural awareness of potential health issues related to LGBT individuals and families (Carabez et al. 2015a). Some studies supported the inclusion and embedding of LGBT concerns and issues into the broader healthcare curriculum to complement interpersonal and communication skills development 
(Glendron et al. 2013; Sequeria et al. 2012). In order to address health inequalities and support inclusive practices, including affirmative approaches, there needs to be the full backing of relevant professional regulatory bodies to include LGBT+ content in the health curricula (Strong and Folse 2014).

\section{Discussion}

In many countries across the world there have been major legislative developments that have recognised and strengthened the position of LGBT+ people (World Health Organization 2013). These advancements have enshrined within legislation the fundamental human rights and equality directives necessary to tackle discrimination, marginalisation and social exclusion. The positive legislative developments include human rights, civil partnership, marriage equality, adoption and fostering (Henry \& Wetherell 2017). Despite the important evolving legislative context that provides protection for LGBT+ people, there remain challenges that need to be addressed within the healthcare arena. The key findings from this systematic review have revealed significant gaps in the development of cultural competence in LGBT+ health issues for undergraduate students and practitioners and the limited availability of appropriate education and training opportunities. Addressing this is necessary as education and training can result in the acquisition of important knowledge and skills, an opportunity to question attitudes and beliefs, and explore ways to reduce stigma and implement best practice approaches to providing appropriate, responsive and affirmative care.

The review has highlighted the importance of developing curricula that is influenced by the latest evidence and include learning about key terminology, stigma and discrimination, sexuality and sexual concerns, talking about sex and LGBT+ -specific health issues and heath disparities (Chen and Yang 2015; Echenzona-Johnson 2017; Sekoni et al. 2017). Educational programmes 
should be supported by professional organisations such as the Medical Colleges, Royal College of Nursing and The General Medical Council; international bodies such as the United Nations and World Health Organisation (WHO); and non-statutory groups such as Stonewall in the United Kingdom (UK). A recent educational initiative between Cardiff University and Stonewall involved embedding LGBT+ -specific content in their undergraduate nursing courses in order to create a more inclusive health curriculum (Pearce 2017).

It has become increasingly clear from this review that opportunities exist for the development and inclusion of LGBT+ -specific needs and issues within undergraduate, postgraduate and continuing professional development (CPD) programmes (Carabez et al. 2015a; Gendron et al. 2013; Groz et al. 2017; Kelley et al. 2008). It has become evident that there is an absence of studies that relate to cross-disciplinary learning at undergraduate level. Inter-professional teaching and learning approaches could be utilized to support practitioners to develop awareness, clinical expertise and skills to work competently, ethically and effectively with LGBT+ clients and their families (Freeth et al. 2008). Learners would be able to share experiences, develop interpersonal and communication skills, question their own attitudes and biases, reflect on key issues and identify LGBT+ -specific psychosocial and health concerns. Although the review has highlighted important concerns for practice developments, some initiatives do exist, mainly in the United States (US), that address LGBT+ clinical competence training and education that is provided by community-based organisations and healthcare agencies. A good example is the National LGBT Health Education Center at the Fenway Institute where practitioners receive awareness, knowledge and skills training to work more effectively with LGBT+ client groups (Reisner et al. 2015).

It is evident from the wider research literature related to LGBT+ people, that they continue to experience discrimination and barriers to accessing healthcare which further contributes to their 
poor health and social exclusion (McCann and Brown 2017; McCann and Sharek 2016). Given the extent of the research evidence in the area, there is a need to undertake further studies focusing on LGBT+ health in the undergraduate curriculum that are international and multi-centred. This would allow for studies to be undertaken between different universities, countries and continents thereby allowing larger samples with a wider international and transcultural focus thus enabling comparisons to be made. There is also a need to research the impact and outcomes of the inclusion of LGBT+ health within the undergraduate health curriculum and continuing professional development programmes. Therefore, there is an opportunity to undertake longitudinal studies focusing on pre- and post-evaluation LGBT+ health education and training programmes to identify change over time. There is currently no available research evidence identifying the long-term impact of including LGBT+ health within the undergraduate health curriculum or CPD programmes. There are no research studies that have studied the impact of including LGBTQ health within education initiatives from the perspective of patients who are LGBT+. This would enable the identification of changes in attitudes, values, confidence, competence and improved knowledge and skills leading to the delivery of culturally sensitive and positive, affirmative approach to care, treatment and support.

\section{Strengths and limitations}

This systematic review has identified important issues that need to be addressed to ensure that undergraduate students and health practitioners possess the appropriate knowledge, skills, attitudes and values necessary to meet the distinct health needs of LGBT+ people. Tools have been developed to assist educators, undergraduate students and practitioners to identify areas related to LGBT+ health where further development is required. The identification of areas of best practice about LGBT+ health within the curriculum offers a useful starting point for educators 
to review their current programmes and develop and improve content and assessment strategies. However, in terms of empirical evidence, the review is limited by the paucity of studies, beyond the USA, where most had been conducted. There were no international, multi-centred studies or studies focusing on specific LGBT+ subgroups, such as transgender and intersex people. There were no longitudinal studies identifying the impact of LGBT+ health within education programmes or of the experiences of patients when accessing healthcare. Future research studies should consider ways of addressing these gaps in the existing research evidence-base.

\section{Conclusion}

There are examples of the inclusion and integration of LGBT+ health needs and concerns within undergraduate health curriculum and CPD programmes for practitioners. This is encouraging and necessary given the significant health inequalities and distinct needs experienced by this population. There are examples of best practice in the delivery and evaluation of LGBT+ health within education programmes that offer a helpful starting point to guide developments more widely. It is also apparent from this systematic review that inclusion within health programmes is patchy and limited with a need for a more consistent approach across all undergraduate health programmes for doctors, nurses and other professional disciplines. Similarly, there is a need for continuing professional development opportunities for health and other professionals in the area of LGBT+ health. Longitudinal national and international research collaborations offer a way forward to undertake studies into to the immediate and longer-term impact on practice and health outcomes and experiences, thereby seeking to improve the health and well-being of LGBT+ people. 


\section{References}

Arksey, H., O’Malley, L., 2005. Scoping studies: Towards a methodological framework. Int J Soc Res Methodol 8 (1), 19-32.

Australian Human Rights Commission, 2014. Face the Facts: Lesbian, gay, bisexual, transgender and intersex people. Australian Human Rights Commission, Sydney.

Bariola, E., Lyons, A., Leonard, W., Pitts, M., Badcock, P., Couch, M., 2015. Demographic and psychosocial factors associated with psychological distress and resilience among transgender individuals. Am J Public Health 105, 2108-2116.

Bauer, G.R., Hammond, R., Travers, R., Kaay, M., Hohenadel, K.M.,Boyce, M., 2009. 'I don't think this is theoretical, this is our lives': How erasure impacts health care for transgender people. J Assoc Nurses AIDS Care 20 (5), 348-361.

Behar-Horenstein, L.S., Feng, X., 2017. Enhancing Cultural Competence Among Dental Students Through Active Teaching and Experiential Learning. Qual Rep 22 (4), 1169.

Bidell, M., 2017. The Lesbian, Gay, Bisexual, and Transgender Development of Clinical Skills Scale (LGBTQ-DOCSS): Establishing a New Interdisciplinary Self-Assessment for Health Providers. J Homosex 64 (10), 1432-1460. doi: 10.1080/00918369.2017.1321389.

Cahill, S., Makadon, H., 2013. Sexual orientation and gender identity data collection in clinical settings and in electronic health records: A key to ending LGBT health disparities. LGBT Health $1(1), 34-41$.

Carabez, R., Pellegrini, M., Mankovitz, A., Eliason, M.J., Dariotis, W.M., 2015a. Nursing students' perceptions of their knowledge of lesbian, gay, bisexual, and transgender issues: Effectiveness of a multi-purpose assignment in a public health nursing class. J Nurs Educ 54 (1), 50-53. doi: 10.3928/01484834-20141228-03.

Carabez, R., Pellegrini, M., Mankovitz, A., Eliason, M., Ciano, M., Scott, M., 2015b. 'Never in All My Years'...: Nurses' Education About LGBTQ Health. J Prof Nurs 31 (4), 323-329.

Corliss, H.L., Shankle, M.D., Moyer, M.B., 2007. Research, curricula, and resources related to lesbian, gay, bisexual, and transgender health in US schools of public health. Am J Public Health (6), 1023-1027.

Daley, A., MacDonnell, J.A., 2015. 'That would have been beneficial': LGBTQQ education for home-care service providers. Health Soc Care Community 23 (3), 282-291.

Dearing, R.L., Hequembourg, A.L., 2014. Culturally (in)competent: Dismantling health care barriers for sexual minority women. Soc Work Health Care 53, 739-761.

Department of Health, 2013. Healthy Ireland: A framework for improved health and well-being 2013-2025. Department of Health, Dublin. 
Echezona-Johnson, C., 2017. Evaluation of Lesbian, Gay, Bisexual, and Transgender Knowledge in Basic Obstetrical Nursing Education. Nurs Educ Perspect 38 (3), 138-142. doi:

10.1097/01.NEP.0000000000000136.

Enson, S., 2015. Causes and consequences of heteronormativity in healthcare and education. British Journal of School Nursing 10 (2), 73-78.

Formby E. 2017 How should we 'care' for LGBT+ students within higher education? Pastoral Care in Education 35(3):203-20.

Fredriksen-Goldsen, K.I., Woodford, M.R., Luke, K.P., Gutiérrez, L., 2011. Support of sexual orientation and gender identity content in social work education: Results from national surveys of US and Anglophone Canadian faculty. J Soc Work Educ 47 (1), 19-35.

Fredriksen-Goldsen KI. The future of LGBT+ aging: a blueprint for action in services, policies, and research. Generations. 2016 Jul 15;40(2):6-15.

Freeth, D., Hammick, M., Reeves, S., Koppel, I., Barr, H., 2008. Effective Interprofessional Education: Development, Delivery and Evaluation. Wylie-Blackwell, London.

Gendron, T., Maddux, S., Krinsky, L., White, J., Lockeman, K., Metcalfe, Y., Aggarwal, S., 2013. Cultural competence training for healthcare professionals working with LGBTQ older adults. Educ Gerontol 39 (6), 454-463.

Grant, M., Mottet, L.A., Tanis, J., 2011. Injustice at Every Turn: A Report of the National Transgender Discrimination Survey. National Center for Transgender Equality, Washington D.C.

Grossman, A.H., D'Augelli, A.R., Frank, J.A., 2011. Aspects of psychological resilience among transgender youth. J LGBT Youth 8(2), 103-115.

Grosz, A.M., Gutierrez, D., Lui, A.A., Chang, J.J., Cole-Kelly, K., Ng, H., 2017. A Student-Led Introduction to Lesbian, Gay, Bisexual, and Transgender Health for First-Year Medical Students. Fam Med 49 (1), 52-56.

Hardacker, C.T., Rubinstein, B., Hotton, A., Houlberg, M., 2014. Adding silver to the rainbow: The development of the nurses' health education about LGBTQ elders (HEALE) cultural competency curriculum. J Nurs Manag 22 (2), 257-266.

Health Service Executive, 2009. LGBT Health: Towards Meeting the Healthcare Needs of Lesbian, Gay, Bisexual and Transgender People. Health Service Executive, Dublin.

Hendricks, M.L., Testa, R.J., 2012. A conceptual framework for clinical work with transgender and gender nonconforming clients: An adaptation of the Minority Stress Model. Prof Psychol Res $\operatorname{Pr} 43,460-467$.

Henry PJ, Wetherell G. 2017. Countries with greater gender equality have more positive attitudes and laws concerning lesbians and gay men. Sex Roles 77(7-8), 523-32. 
Institute of Medicine, 2011. The Health of Lesbian, Gay, Bisexual, and Transgender People. The National Academies Press, Washington, D.C.

Kelley, L., Chou, C.L., Dibble, S.L., Robertson, P.A., 2008. A critical intervention in lesbian, gay, bisexual, and transgender health: knowledge and attitude outcomes among second-year medical students.Teach Learn Med 20 (3), 248-253.

Kelly, P.J., 2012. Should we rethink how we teach cultural competency in physician assistant education? J Physician Assist Educ 23 (3), 42-45.

King, M., Semlyen, J., Tai, S.S., Killaspy, H., Osborn, D., Popelyuk, D. \& Nazareth, I. (2008). A systematic review of mental disorder, suicide, and deliberate self-harm in lesbian, gay and bisexual people. BMC Psychiatry 8, 1-17.

Kuyper, L., \& Fokkema, T. (2011). Minority stress and mental health among Dutch LGBs: examination of differences between sex and sexual orientation. J Couns Psychol 58 (2), 222-233.

Lim, F.A., Bernstein, I., 2012. Promoting awareness of LGBTQ issues in aging in a Baccalaureate Nursing Program. Nurs Educ Perspect 33 (3), 170-175.

Lim, F., Johnson, M., Eliason, M., 2015. A national survey of faculty knowledge, experience, and readiness for teaching lesbian, gay, bisexual, and transgender health in baccalaureate nursing programs. Nurs Educ Perspect 36 (3), 144-152.

Mayock, P., Bryan, A., Carr, N., Kitching, K., 2008. Supporting LGBT lives: A study of mental health and well-being. National Office for Suicide Prevention, Dublin.

Mays, N., Pope, C. \& Popay, J. (2005) Details of approaches to synthesis a methodological appendix to the paper: systematically reviewing qualitative and quantitative evidence to inform management and policy making in the health field. Technical Report. Canadian Health Services Research Foundation/NHS Service Delivery and Organisation R\&D Programme, Ottawa, Canada / London, UK.

McCann, E., Sharek, D. 2013. Survey of lesbian, gay, bisexual and transgender people's experiences of mental health services in Ireland. Int J Ment Health Nurs 23 (2), 118-127.

McCann, E., Sharek, D., 2016. Mental health needs of people who identify as transgender: A review of the literature. Arch Psychiatr Nurs 30 (2), 280-285.

McCann, E., Brown, M., 2017. Discrimination and resilience and the needs of people who identify as Transgender: A narrative review of quantitative research studies. J Clin Nurs (Early View) DOI: 10.1111/jocn.1391. 
Meyer, I.H., 2015. Resilience in the study of minority stress and health of sexual and gender minorities. Psychology of Sexual Orientation and Gender Minorities 2 (3), 209.

Obedin-Maliver, J., Goldsmith, E.S., Stewart, L., White, W., Tran, E., Brenman, S., Wells, M., Fetterman, D.M., Garcia, G., Lunn, M.R., 2011. Lesbian, gay, bisexual, and transgender-related content in undergraduate medical education. Jama 306 (9), 971-977.

Ontario Human Rights Commission, 2014. Policy on Preventing Discrimination Because of Gender Identity or Gender Expression. Ontario Human Rights Commission, Ontario.

Parameshwaran, V., Cockbain, B.C., Hillyard, M., Price, J.R., 2017. Is the lack of specific lesbian, gay, bisexual, transgender and queer/questioning (LGBTQQ) health care education in medical school a cause for concern? Evidence from a survey of knowledge and practice among UK medical students. J Homosex 64 (3), 367-381.

Pearce, L., 2017. Making nurse education LGBT-friendly. Nurs Stand 31 (23), 22-24, doi: 10.7748/ns.31.23.22.s23

Reisner, S.L., Bradford, J., Hopwood, R., Gonzalez, A., Makadon, H., Todisco, D., Cavanaugh, T., VanDerwarker, R., Grasso, C., Zaslow, S., Boswell, S.L., 2015. Comprehensive transgender healthcare: the gender affirming clinical and public health model of Fenway Health. Journal of Urban Health, 92 (3), 584-592.

Ripley, M., Anderson, E., McCormack, M., Rockett, B., 2012. Heteronormativity in the university classroom: Novelty attachment and content substitution among gay-friendly students. Sociology of Education 85 (2), 121-130.

Rogers, A., Rebbe, R., Gardella, C., Worlein, M., Chamberlin, M., 2013. Older LGBTQ adult training panels: An opportunity to educate about issues faced by the older LGBTQ community. $J$ Gerontol Soc Work 56 (7), 580-595.

Röndahl, G., 2011. Heteronormativity in health care education programs. Nurse Educ Today 31(4), 345-349.

Royal College of General Practitioners (Northern Ireland), 2015. Guidelines of the care of Lesbian, Gay, Bisexual Patients in Primary Care. Royal College of General Practitioners, Belfast.

Royal College of Nursing, 2016. Caring for Lesbian, Gay, Bisexual and Trans Clients or Patients: Guide for Nurses and Health Care Support Workers on Next-of Kin Issues. RCN, London.

Royal College of Nursing, 2017. Fair care for trans patients: an RCN guide for nursing and health professionals. RCN, London.

Rushbrooke E, Murray C \& Townsend S (2014) The experiences of intimate relationships by people with intellectual disabilities: A qualitative study. J Appl Res Intellect Disabil 27, 531541. 
Sequeira, G.M., Chakraborti, C., Panunti, B.A., 2012. Integrating lesbian, gay, bisexual, and transgender (LGBTQ) content into undergraduate medical school curricula: a qualitative study. Ochsner J 12 (4), 379-382.

Singer, R.B., 2015. LGBTQQ focused education. Int J Childbirth Educ 30 (2), 17-19.

Sirota, T., 2013. Attitudes among nurse educators toward homosexuality. J Nurs Educ 52 (4), 219-227.

Stewart, K., O'Reilly, P., 2017. Exploring the attitudes, knowledge and beliefs of nurses and midwives of the healthcare needs of the LGBTQ population: An integrative review. Nurse Ed Today 53, 67-77.

Strong, K.L., Folse, V.N., 2014. Assessing undergraduate nursing students' knowledge, attitudes, and cultural competence in caring for lesbian, gay, bisexual, and transgender patients. J Nurs Educ 54 (1), 45-49.

Transgender Equality Network Ireland, 2013. Speaking from the margins: Transgender mental health and wellbeing in Ireland. TENI, Dublin.

Vance, S.R., Deutsch, M.B., Rosenthal, S.M., Buckelew, S.M., 2017. Enhancing Pediatric Trainees' and Students' Knowledge in Providing Care to Transgender Youth. J Adolesc Health 60(4), 425-430.

Walsh, D., Hendrickson, S.G., 2015. Focusing on the 'T' in LGBTQ: An online survey of related content in Texas nursing programs. J Nurs Educ 5(6), 347-351.

White, W., Brenman, S., Paradis, E., Goldsmith, E.S., Lunn, M.R., Obedin-Maliver, J., Stewart, L., Tran, E., Wells, M., Chamberlain, L.J., Fetterman, D.M., 2015. Lesbian, gay, bisexual, and transgender patient care: Medical students' preparedness and comfort. Teach Learn Med 27 (3), 254-263.

Willen, S.S., 2013. Confronting a 'big huge gaping wound': Emotion and anxiety in a cultural sensitivity course for psychiatry residents. Cult Med Psychiatry 37 (2), (253-279).

World Health Organization, 2013. Addressing the Causes of Disparities in Health Service Access and Utilization for Lesbian, Gay, Bisexual and Transgender (LGBTQ) Persons. WHO, Geneva. 